\title{
Comparative analysis of modern software for nonlinear analysis: review
}

\author{
I.A. Magomedov \\ Chechen State University, Grozny
}

Annotation: This work outlines software packages that are capable of dealing with nonlinearity of the analyzing structure. Brief introduction of the software and its beginning in the history. Also explained the difference of linear and nonlinear analysis performed on the structure. Defined which software packages are for media and analyzing problem (structure). Similarly, descriptive study was done to understand advantages and disadvantages of main analyzing tools ANSYS, ABAQUS, SOLIDWORKS. In addition, the work looked into which one of the mentioned tools have its own distinguish functions. Finally, the results data of all three software were compared with each other.

Keywords: nonlinear analysis, numerical analysis, ANSYS, ABAQUS, SOLIDWORKS

Not so far, in the past researchers had no idea that by their new discovery (inventions), such as: systems of linear equations, numerical quadrature, the fast Fourier transform and many other discoveries will push the ground to the new era. Computers were invented and from that point numerical mathematics began to explode to open new scope. New journals were introduced to the scientists with the appearance of new technics: Mathematics of Computation (1943) and Numerische Mathematik (1959). After approximately half century from appearance of the new journals computers or in other way machines speed up by a factor of around 109, but also during that time algorithms for solving the same problem were improved (advanced). Therefore, with the combination of those two the computational speed was increased beyond one's comprehension scale. Numerical analysis right now is one of the largest branch of the mathematics and with the dozen journals where scientists can publish their work [1]. Due to the computational power numerical analysis is applicable in many fields. The application of it can be found in all fields of engendering and furthermore: physical sciences, social sciences, medicine, business and some more. Therefore, todays software makes possible nonlinearity or linearity of the structure to be calculated. Nevertheless, to validate such an analysis skilled researcher is required as results could be inaccurate.

To perform any analysis on any structure, researchers will consider whether 
to use linear static analysis or nonlinear analysis for the investigation. Beyond doubt, there is a tremendous difference between these two methods or analytical tools. A linear static analysis has differ relations from nonlinear analysis. Between applied force and displacement there exists linear relation holds. Therefore, this can be used (applicable) to any variety of structural problems, in which stresses continue to hold the linear elastic range of the utilized material. Its simplicity comes from stiffness matrix of the model as it stays constant and thus its computation or solving procedure is moderately short if to be compared with nonlinear analysis of the analogous model. Consequently, before performing a nonlinear analysis the linear static analysis is often preferable. To distinguish between the two approaches that were mentioned before it's important to understand the main difference is relation holds between applied force and displacement. In the first case we got linear holds and second one we god nonlinear holds between applied force and displacement. The problems of nonlinearity can originate from geometrical and material nonlinearity and contact. Geometrical and material nonlinearity comes from a structure with excessive defamation and elastoplastic material consequently. Hens considering those parameters and the influence of those to the analysis, it can be related in resulting to stiffness matrix to be not constant during load application, whereas linear analysis has constant stiffness matrix. Concluding all beforementioned one can assume that for a nonlinear analysis different strategy are required [2].

\section{Modern analysis software}

There are many software packages out in the marked that can perform different task on a different level. These software packages can be divided into two main categories: those with ability to calculate real world data and those with ability to simulate, but no real physics are contributed. Into first category one can choose ANSYS, ABAQUS, SOLIDWORKS (most popular) and so on. Into second category goes software that are used in the media, such as: $3 \mathrm{ds}$ Max, Blender, 
Cinema $4 \mathrm{~d}$ and other related software.

Let' $\mathrm{s}$ discuss about first category and their application in the marked. ANSYS, ABAQUS, SOLIDWORKS are powerful tools when dealing with difficult (complex) geometries and analysis, where the real-world results are required. These software packages have built in functions like 3-dimensional modelling and simulation ability. Complexity of $3 \mathrm{~d}$ modeling and simulation can vary on users' experience. Also, price difference of different software could differ. These software packages are highly expensive for an average user, although there are limited packages for free, therefore they are used mostly in industry.

\section{SOLIDWORKS}

SOLIDWORKS is a tool mainly used for modeling and ANSYS and ABAQUS for simulation. Founder of SOLIDWORKS Jon Hirschtick employed a team in 1993 for building 3d CAD (computer-aided design) software, which would be easy to use, affordable and available on the windows desktop. Nowadays it is the most popular CAD software with overall 3.5 million licenses sold worldwide. Simulation capabilities of the software are vast. It is capable of analyzing: metal fatigue, pressure vessel, thermal structural and many more. Lately, capability of analyzing nonlinearity of the structure. As any other similar tool for simulation nonlinearity of a structure under deformations (general loadings and material conditions) SOLIDWORKS lets engineers to confirm (validate) product (structure) quality performance and safety throughout the design creation. Thus, SOLIDWORKS is a great tool with $3 \mathrm{~d}$ design (modeling) and simulations capability and with easy to use interface, which makes it to stand out from other software package [3].

\section{ANSYS and ABAQUS}

ANSYS was founded earlier in 1970 by John Swanson. At early stage ANSYS brought into its product additional components (fluid dynamics, 
electronics design and other physics analysis) from other engineering design companies, which put it into a leading list in the market. Finite element analysis software package is the main product that ANSYS develops and markets. The software capabilities are immense. Its capabilities are to simulate computer models of electronics, electromagnetics, temperature, elasticity, fluid flow and many others. As same as to SOLIDWORKS ANAYS has build in design tool, where users can start from defining dimensions of the structure by making it into $3 \mathrm{~d}$ model and then applying necessary lodes, pressure, moment force or any other [4].

ABAQUS was released in 1978. ABAQUS is not much different from the other two products as they all serves for one main purpose. However, ABAQUS main direction is automotive and aerospace. Also, its widespread among nonacademic and research institutions in engineering. In addition, the main difference from ANSYS is that ABAQUS has its all plugins or library in one component, whereas other one has not [5].

It can be concluded that all three software packages has their own advantages over one another and some disadvantages. But all software packages are aimed to design and test the structure under some conditions.

Briefly can be outlined second category. 3ds Max, Blender, Cinema 4d these are software mainly used in media, and mostly have nothing to do with science. Interface of these software packages are well distributed in the main window and easy to use, a lot of function to be applied to the structure (modifiers). $3 \mathrm{~d}$ modelling well developed as well as simulation part. However, simulation of the structure does not give the results as it would be given in engineering software. As the real-world date not important as it is mainly made for the visualizing. Therefore, the end result could look good, but have nothing to be related to science.

\section{Results comparison}

Lluís O.A. in his work did comparison analysis using ANSYS and ABAQUS. The main idea of the work was to investigate titanium plate of $1 \mathrm{~m}$ of 
length and with a width of $5 \mathrm{~mm}$ with applied boundary conditions (signal of 50 $\mathrm{kHz}$ and 10 cycles). By observing figure 1 it is clear that the discrepancy is quite noticeable. Although the parameters were kept the same for both software [6]. Work done by the researchers of university of Ural on heat exchange conclude that most close results were gathered by software SOLIWORKS. The other two software packages were way to far from validation.

\begin{tabular}{cccc}
\hline & Memory (Mb) & File i/o (Mb/s) & Total Time (h) \\
\hline ANSYS & 112 & 42.9 & 5.24 \\
ABAQUS & 111 & 25.1 & 0.1834 \\
\hline
\end{tabular}

Fig. 1. Results gathered by ABAQUS and ANSYS.

\section{Conclusion}

To conclude, comparative analysis was done on software packages in terms to study whether they are capable of working out nonlinearity of the problem. Results illustrated that all three software were able to deal with the nonlinearity. It was also noted that depending on the problem it is wiser to chose the most suited software package. Also, the knowledge of the examiner is vital as the end results will depend on the assumption made at the beginning.

\section{References}

1. Lloyd N. T. Numerical Analysis, Oxford University, 2006, pp 3-4.

2. Femto.Eu In FEA, what is linear and nonlinear analysis?. 2017. URL: femto.eu/stories/linear-non-linear-analysis-explained/

3. Solidworks Company History. Solidworks company website URL: solidworks.com/sw/183_ENU_HTML.htm

4. Ansys. Pennsylvania Technology Directory. 1999. p. 25.

5. Abaqus FEA, SIMULIA web site. Dassault Syst è mes, 2010. URL: 3ds.com/products-services/simulia, 
6. Lluís O. A., Comparison between ansys and abaqus using ultrasonic Guided waves Department of Mechanical Engineering École de Téchnologie Supé rieure. Montréal, Canada, 2014. pp 75-76.

7. Chernykh V. N., Ilyukhin P. A, Shagabutdinov T. F., Dubinin A. M., Denisov M. A. Comparative modeling and testing of the adequacy of the calculations of the heat exchanger in engineering modeling packages, 2017. pp. 266-268.

8. Magomedov I. A., Mezhieva A.I., Suleymanova M.A. Inženernyj vestnik Dona (Rus). 2018. №4. URL: ivdon.ru/ru/magazine/archive/n4y2018/5334

9. Magomadov V.S. Quantum computing, quantum theory and artificial intelligence. Inženernyj vestnik Dona (Rus). 2018. №4. URL: ivdon.ru/ru/magazine/archive/n4y2018/5424

10. Hill, M.; Tiedeman, C. (2007). Effective Groundwater Model Calibration, with Analysis of Data, Sensitivities, Predictions, and Uncertainty. John Wiley \& Sons. pp. 26-40. 